\title{
Não ando só! Homenagem às professoras do Departamento de Filosofia da USP ${ }^{1}$
}

\author{
Tessa Moura Lacerda ${ }^{2}$
}

Resumo: Neste relato, tenho a difícil e honrosa tarefa de me colocar ao lado de grandes mulheres, professoras do Departamento de Filosofia da Universidade de São Paulo, recuperando muito brevemente aspectos de minha trajetória pessoal.

Palavra-chave: Filosofia - História - Departamento de Filosofia- FFLCH-USP - Gênero Professoras

\section{I don't walk alone! Tribute to the professors of the Department of Philosophy} at USP

\begin{abstract}
In this report, I have the difficult and honorable task of placing myself beside great women, professors of the Department of Philosophy of the University of São Paulo, recovering very briefly aspects of my personal trajectory.

Keywords: Philosophy - History - Department of Philosophy- FFLCH-USP - Gender - Teachers

\footnotetext{
${ }^{1}$ Este pequeno texto não é propriamente um artigo, mas uma homenagem a minhas professoras, hoje colegas, homenagem que foi proferida no encerramento do II Encontro do GT Filosofia e Gênero, no dia 6 de setembro de 2019, no Departamento de Filosofia da USP. É um texto escrito para ser falado, não lido, por isso peço a generosidade do leitor. $\mathrm{O}$ artigo com o qual efetivamente participei dos debates sobre gênero na ocasião do Encontro, e que deveria fazer parte do presente dossiê, "A 'questão feminina' e uma questão feminista: identidade", foi publicado em número anterior a este, dos Cadernos de Ética e Filosofia Política (n. 37, volume 2, pp. 147-160, 2020).

2 Professora da Universidade de São Paulo (USP), São Paulo, Brasil. E-mail: tessalacerda@usp.br
} 
"Minha mãe me deu ao mundo

De maneira singular

Me dizendo a sentença

Pra eu sempre pedir licença

Mas nunca deixar de entrar"3

"Toda história é história contemporânea: tem um compromisso com o presente", sugere Carla Pinsky na introdução ao livro de Michelle Perrot. A história interroga o passado com questões presentes. Ou, nas palavras de Ranke retomadas por Norbert Elias, "a história está sempre sendo reescrita... Cada época, com sua orientação principal, apropria-se dela"5; de modo que as situações vigentes contemporâneas determinam a maneira como se olha a história. E é assim, creio, que se faz história da filosofia também. Se hoje propomos inscrever o nome de mulheres na história da filosofia, por exemplo, é porque temos um compromisso com nosso presente. Não se trata apenas, nem simplesmente de "fazer justiça" às mulheres que nos antecederam e cujas vozes às vezes foram abafadas, mas de nos colocarmos como herdeiras delas. E como herdeiras também de todas aquelas de quem ouvimos apenas um burburinho indiscernível, como o caminhante leibniziano que, à beira mar, percebe o infinito, percebe cada gota de água, mas só é capaz de se aperceber do som da onda inteira.

Virginia Woolf sugere essa ideia quando afirma em um ensaio escrito em 1928, Um quarto só seu, que "a experiência coletiva está por trás da voz individual”", e que "cada livro é a continuação de um outro, apesar de nosso hábito de julgá-los separadamente" . Mas para que essa tradição seja constituída é preciso reconhecer essas precursoras. Virginia Woolf se refere às romancistas do século XIX, mas acho que vale também para nós aqui e agora, quando ela diz que:

quando iam pôr os pensamentos no papel (...) [essas escritoras] não eram amparadas por nenhuma tradição ou (...) dispunham apenas de uma tradição tão recente e parcial que não servia de grande ajuda. Pois, quando somos mulheres, pensamos o passado por intermédio de nossas mães. É inútil recorrer aos grandes escritores homens em busca de ajuda, por mais que possamos recorrer a eles em busca de prazer. $^{8}$

$*$

Há quatro anos, em 2015, tive a honra de participar de uma homenagem à professora Maria das Graças, organizada por seus ex-alunos de Ética e Filosofia Política. Foi uma ocasião deliciosa e a primeira vez que elaborei uma reflexão sobre a relação entre o feminino e a filosofia e, particularmente, sobre a presença feminina em nosso Departamento de Filosofia da USP.

\footnotetext{
${ }^{3}$ Música "Tudo de novo" de Caetano, cantada por Maria Bethânia no álbum Maria Bethânia ao vivo, de 1970.

4 PINSKY, “Apresentação", p. 11.

${ }^{5}$ ELIAS, $A$ sociedade de corte, p. 30.

${ }^{6} \mathrm{WOOLF}$, Um quarto só seu, cap. 4, p. 89.

${ }^{7}$ WOOLF, Um quarto só seu, cap. 4, p. 110.

${ }^{8}$ WOOLF, Um quarto só seu, cap. 4, p. 103.
} 
Há três anos, em 2016, ajudei a organizar com os colegas do Grupo de Estudos Espinosanos uma homenagem à professora Marilena Chaui, as "Jornadas Marilena Chaui". Deste encontro resultou um número especial dos Cadernos espinosanos, que edito há treze anos, com ensaios dos antigos alunos de Marilena Chaui, eu inclusive. Tive, então, a oportunidade de falar um pouco sobre esta relação, para dizer o mínimo, inspiradora, que tenho com esta querida professora e com sua obra monumental, em particular a obra sobre Espinosa, com a qual minhas reflexões sobre Leibniz sempre dialogaram.

Há um ano, em 2018, fui convidada a participar de mais uma homenagem à professora Marilena Chaui na Universidade de Brasília, onde ela merecidamente recebeu o título de Doutora Honoris causa. Pude, então, continuar aquele diálogo há tempos iniciado. Diálogo sobre a singularidade que nos define, o desejo como essência e as buscas constitutivas de quem não está em beatitude.

Participei, há um ano também, de uma atividade de greve no Espaço Verde (nossa antiga biblioteca e onde hoje estão os Centros Acadêmicos da Filosofia e das Sociais) sobre as professoras do Departamento de Filosofia da USP. Lá falei de improviso, já que minha participação não estava inicialmente prevista. O que podia significar um embaraço - o improviso - na verdade mostrou-se favorável, porque não pude meditar longamente sobre o significado de minha fala e de minha presença ali ao lado de Marilena, Maria Lúcia, Maria e Silvana.

Confesso que hoje me vejo numa posição, no mínimo, incômoda, nesta mesa que reúne minhas professoras e antigas professoras deste Departamento. Todas, de alguma forma, importantes, para que eu esteja também aqui: Otilia Arantes; Scarlett Marton; Silvana Ramos; Olgária Matos, querida, amiga; Andrea Loparic, minha querida professora de Lógica e amiga que me fala da militância política na ditadura de 1964-85 (para quem não sabe, Andrea foi uma das fundadoras da AP, Ação Popular, partido no qual, depois, militaram meus pais). Hoje dou aula para sua neta em meu curso de graduação. Maria Lúcia, companheira, minha professora desde meu primeiro semestre de graduação, amiga de festas e da alegria de viver. Maria da Graças, querida, amiga, sempre tão cuidadosa, sempre atenciosa. Marilena Chaui, o que dizer? Minha mãe intelectual.

Como, diante destas mulheres com tanta história, fazer o que me foi pedido e narrar brevemente minha "trajetória"?

O filme sobre Gilda de Mello e Souza talvez seja a única dica sobre como fazer isso, quando exibe não apenas a obra importantíssima de nossa pioneira neste Departamento. Gilda foi, com efeito, pioneira na discussão do feminino, como destacou Marilena Chaui em outra ocasião", ao escrever também sobre moda em um tempo em que o tema "talvez tenha parecido fútil a muita gente"10, como afirma a própria Gilda na apresentação de seu livro, publicado 36 anos depois de escrito como tese de doutorado. Gilda teve a coragem de elaborar, nas palavras de Marilena Chaui, "um pensamento novo sobre a Estética"11, coragem que se manifestou também quando assumiu a chefia deste Departamento em plena ditadura, em 1970 e, para afastar o risco de intervenção, conseguiu garantir em um ano e meio a defesa de quatro mestrados, um doutorado e uma livre-docência para preencher os quadros do

\footnotetext{
9 Cf. conferência "Gilda e Clarice: a dignidade do feminino" no colóquio Mulheres na Filosofia Moderna, Rio de Janeiro 17 a 20/06/19, publicado posteriormente em CHAUI, 2020.

${ }^{10}$ MELLO E SOUZA, O espirito das roupas, apud CHAUI, "Gilda e Clarice: a dignidade do feminino", p. 15.

11 CHAUI, "Gilda e Clarice: a dignidade do feminino", p. 14.
} 
Departamento, como narra Marilena. Mas, dizia eu, o filme Exercícios do olhar - para falar de Gilda de Mello e Souza, é minha dica para enfrentar esta difícil posição nesta mesa cheia de História, porque mostra não apenas a obra inovadora, a ousadia e a coragem da professora deste Departamento, mas também a Gilda menina, de vestido branco e laço no cabelo, em foto de estúdio, ou de vestido estampado, um pouquinho mais velha, na fazenda em Araraquara, quando a voz em off narra a relação de Gilda com Mario de Andrade.

É da infância, então, que passo a falar. Nasci em 1974, na ditadura. Meu pai, Gildo Macedo Lacerda havia sido morto sob tortura alguns meses antes. Minha mãe, Mariluce Moura, bravamente enfrentara já grávida prisão, tortura, viuvez e, então, a maternidade sozinha. Não posso deixar de mencionar isso, porque, se eu puder falar de uma trajetória, a minha é marcada pela busca de compreensão do que nos constitui intimamente como indivíduos singulares - e por isso, o encontro com Leibniz e o sujeito que é uma parte-total, um mundo, sujeito que exprime a totalidade de que faz parte de um ponto de vista único sobre os acontecimentos que narram a história do mundo.

Por isso, também, mais recentemente, e muito incentivada (ou instigada) por Marilena Chaui, minha reflexão sobre o tempo, a memória e a história. E sobre o papel do testemunho, primeiro, no pensamento de uma história que não é linear e progressiva, mas na qual o passado emerge no presente, e, segundo, na elaboração de uma narrativa histórica que fale, para usar a expressão de W. Benjamin, dos vencidos.

Nasci em uma família matriarcal - não por minha mãe estar viúva, mas por minha avó ter sido uma mulher forte, generosa e guerreira, que também ficou viúva quando eu tinha menos de dois anos. Apenas sei do avô amoroso que tive pelo relato das mulheres da família. E são muitas mulheres. Havia as duas irmãs mais velhas de minha avó, e há minhas cinco tias maternas, sempre muito presentes e muito mais marcantes do que os quatro, dos cinco tios, que pude conhecer. Nasci em uma família de mulheres, boa parte delas, militantes de esquerda.

E acho, que um tanto instintivamente procurei, neste Departamento tão masculino, construir uma "família" de mulheres. Claro que meu querido professor Franklin Leopoldo e Silva será sempre o meu mestre. Mas convivo, semanalmente, há vinte e três anos, com Marilena Chaui e com o Grupo de Estudos Espinosanos coordenado por ela. O Departamento de Filosofia da USP foi perdendo nas décadas mais recentes quadros femininos, tanto entre os professores - somos apenas duas professoras na ativa, e temos trinta e três colegas homens na ativa (não consigo deixar mencionar estes números!). Somos treze mulheres ao longo de toda história deste Departamento -, como entre os estudantes de graduação e de pós-graduação, um fenômeno que não é exclusivo da USP e que foi apontado recentemente pela pesquisa da professora Carolina Araújo da UFRJ ${ }^{12}$. Se a presença feminina é reduzida entre aqueles que fazem Filosofia, o Grupo de Estudos Espinosanos, na contramão disso, é um oásis: há sempre tantas ou mais mulheres do que homens no grupo (e não estabelecemos cotas para isso). É um privilégio e uma honra poder pensar junto com mulheres e homens, sem ter que se afirmar como mulher e como intelectual a cada palavra, poder ouvir e ser ouvida por todas e todos.

12 ARAÚJO, "Quatorze anos de desigualdade: mulheres na carreira acadêmica de Filosofia no Brasil entre 2004 e 2017". 
É um espaço singular de debate, com certeza. E é este clima democrático (e sabemos que a democracia acolhe o conflito) que busco reproduzir com alunas e alunos. Gosto de ouvir alunas e alunos - e é desta escuta que nasceram meus cursos (e pesquisas) mais recentes sobre os feminismos. Gosto de ouvir alunas e alunos, porque como já ouvi de Marilena algumas vezes, a grande professora/professor não é aquela/e que ensina a fazer como ela ou ele. A grande professora, o grande professor convida os alunos a fazer com ela ou ele. A fazer junto.

\section{Referências bibliográficas}

ARAÚJO, Carolina. "Quatorze anos de desigualdade: mulheres na carreira acadêmica de Filosofia no Brasil entre 2004 e 2017”. Cadernos de Filosofia Alemã: Crítica e Modernidade, 24(1), 13-33, 2019.

CHAUI, Marilena. "Gilda e Clarice: a dignidade do feminino". Revista Ideação, No. 42, Julho/Dezembro de 2020.

ELIAS, Norbert. A sociedade de corte. Rio de Janeiro: Zahar, 1996.

MELLO E SOUZA, Gilda. O espirito das roupas. São Paulo: Companhia das Letras, 1987.

PINSKY, Carla. "Apresentação”. In: PERROT, Michelle. Minha história das mulheres. São Paulo: Contexto, 2017.

WOOLF, Virginia. Um quarto só seu [A Room of One's Own]. Porto Alegre, L\&PM, 2019. 